\title{
Mechanistic investigation of the iridium-catalysed alkylation of amines with alcohols
}

\author{
Fristrup, Peter; Tursky, Matyas; Madsen, Robert
}

Published in:

Organic \& Biomolecular Chemistry

Link to article, DOI:

$10.1039 / \mathrm{c} 2 \mathrm{ob} 06603 \mathrm{c}$

Publication date:

2012

Document Version

Publisher's PDF, also known as Version of record

Link back to DTU Orbit

Citation (APA):

Fristrup, P., Tursky, M., \& Madsen, R. (2012). Mechanistic investigation of the iridium-catalysed alkylation of amines with alcohols. Organic \& Biomolecular Chemistry, 10(13), 2569-2577.

https://doi.org/10.1039/c2ob06603c

\section{General rights}

Copyright and moral rights for the publications made accessible in the public portal are retained by the authors and/or other copyright owners and it is a condition of accessing publications that users recognise and abide by the legal requirements associated with these rights.

- Users may download and print one copy of any publication from the public portal for the purpose of private study or research.

- You may not further distribute the material or use it for any profit-making activity or commercial gain

- You may freely distribute the URL identifying the publication in the public portal

If you believe that this document breaches copyright please contact us providing details, and we will remove access to the work immediately and investigate your claim. 


\title{
Organic \& \\ Biomolecular \\ Chemistry
}

Cite this: Org. Biomol. Chem., 2012, 10, 2569

wWw.rsc.org/obc

PAPER

\section{Mechanistic investigation of the iridium-catalysed alkylation of amines with alcohols $\uparrow$}

\author{
Peter Fristrup,* Matyas Tursky and Robert Madsen*
}

Received 20th September 2011, Accepted 10th January 2012

DOI: $10.1039 / \mathrm{c} 20 \mathrm{b06603c}$

The $\left[\mathrm{Cp}^{*} \mathrm{IrCl}_{2}\right]_{2}$-catalysed alkylation of amines with alcohols was investigated using a combination of experimental and theoretical methods. A Hammett study involving a series of para-substituted benzyl alcohols resulted in a line with a negative slope. This clearly documents that a positive charge is built up in the transition state, which in combination with the measurement of a significant kinetic isotope effect determines hydride abstraction as being the selectivity-determining step under these conditions. A complementary Hammett study using para-substituted anilines was also carried out. Again, a line with a negative slope was obtained suggesting that nucleophilic attack on the aldehyde is selectivity-

determining. A computational investigation of the entire catalytic cycle with full-sized ligands and substrates was performed using density functional theory. The results suggest a catalytic cycle where the intermediate aldehyde stays coordinated to the iridium catalyst and reacts with the amine to give a hemiaminal which is also bound to the catalyst. Dehydration to the imine and reduction to the product amine also takes place without breaking the coordination to the catalyst. The fact that the entire catalytic cycle takes place with all the intermediates bound to the catalyst is important for the further development of this synthetic transformation.

\section{Introduction}

The carbon-nitrogen bond is one of the most abundant covalent bonds in organic chemistry and biochemistry and methods for formation of $\mathrm{C}-\mathrm{N}$ bonds belong to the very heart of organic synthesis. In most cases, $\mathrm{C}-\mathrm{N}$ bonds are formed by substitution of a suitable leaving group or by reductive amination from a carbonyl compound. These reactions, however, employ stoichiometric reagents or produce stoichiometric amounts of waste. In recent years, there has been an increasing awareness of the environmental impact of many chemical processes and research has been directed towards more atom economical and sustainable reactions. ${ }^{1}$ This has led to the development of new methods for the formation of $\mathrm{C}-\mathrm{N}$ bonds and one of the most promising is the direct metal-catalysed alkylation of amines with alcohols. ${ }^{2,3}$ Besides alkylating simple amines this transformation can also be used for synthesis of various heterocyclic ring systems ${ }^{4}$ such as pyrrolidines, ${ }^{5}$ piperidines, ${ }^{5}$ piperazines, ${ }^{6}$ quinolines ${ }^{7}$ and indoles. $^{8}$ The reaction can be achieved with ruthenium ${ }^{2}$ and

Department of Chemistry, Technical University of Denmark, Building 201, 2800 Kgs, Lyngby,Denmark.E-mail:pf@kemi.dtu.dk,rm@kemi. dtu.dk; Fax: (+45) 45933968

$\dagger$ Electronic supplementary information (ESI) available: Experimental data from kinetic runs, KIE determination, XYZ coordinates, SCF energies, Gibbs free energies and IRC scan calculations. See DOI: 10.1039/ c2ob06603c iridium $^{3}$ catalysts where the iridium complex $\left[\mathrm{Cp}^{*} \mathrm{IrCl}_{2}\right]_{2}$ has been one of the most effective catalysts. ${ }^{9}$ The proposed mechanism involves dehydrogenation of the alcohol to the corresponding carbonyl compound followed by imine formation and hydrogenation to the amine with the hydride-complex formed in the first step (Scheme 1). The reaction only produces a molecule of water as by-product and does not require any stoichiometric additives but only a catalytic amount of a base, e.g. carbonate. The dehydrogenation of an alcohol and the hydrogenation of an imine are also the key transformations in the transfer hydrogenation of ketones and imines with isopropanol or formic acidtriethyl amine. ${ }^{10}$ In this connection, the mechanism has been studied both experimentally ${ }^{11}$ and theoretically, ${ }^{12}$ but mainly with ruthenium complexes. Although, a number of iridium

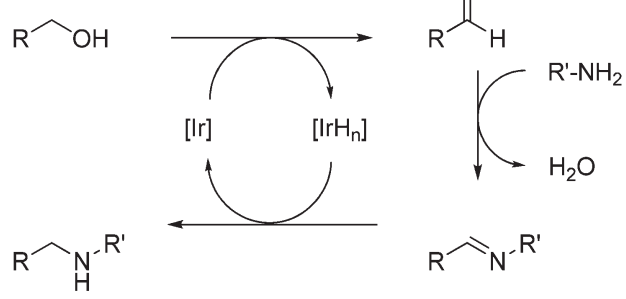

Scheme 1 Simplified catalytic cycle for iridium-catalysed alkylation of amines with alcohols. 
complexes catalyse the transfer hydrogenation of ketones and imines, the mechanism of these reactions has not been as extensively studied as in the case of ruthenium. ${ }^{13}$ Notably, all the investigated iridium complexes were shown to transfer hydrogen from secondary alcohols to ketones through an iridium-monohydride pathway. $^{13}$

Recently, the alkylation of amines with alcohols was studied by Crabtree, Eisenstein and co-workers using density functional theory. ${ }^{14}$ In this investigation $\left[\mathrm{CpIrCl}_{2}\right]_{2}$ with the unsubstituted $\mathrm{Cp}$ ligand was employed and methanol and methylamine were used as the models for the alcohol and the amine, respectively. Interestingly, the carbonate counterion was found to participate actively in the deprotonation of the alcohol and also in the protonation of the formed amine. Furthermore, this computational study predicts that dissociation of the amine is the rate-determining step, which was shown to correlate with experimental data as the weakly basic $\mathrm{TsNH}_{2}$ was found to react faster than aniline.

Herein, we describe a combined experimental and theoretical mechanistic investigation of the alkylation of amines with alcohols in the presence of the $\left[\mathrm{Cp}^{*} \mathrm{IrCl}_{2}\right]_{2}$ catalyst. The experimental study is conducted under conditions relevant for application in organic synthesis with equimolar amounts of amine and alcohol. The electronic influence on the rate of the reaction was investigated by performing two Hammett studies using competition experiments. Furthermore, the primary kinetic isotope effect was determined and the nature of the iridium-hydride complex was investigated. The computational part of the present study includes the full $\mathrm{Cp}^{*}$ ligand in combination with benzyl alcohol and aniline substrates, which allows a direct comparison between experiment and theory.

\section{Results and discussion}

\section{Alcohol oxidation}

The electronic influence on the rate of the initial alcohol oxidation was studied using several para-substituted benzyl alcohols, i.e. a Hammett study. ${ }^{15}$ These Hammett studies were performed as a series of competition experiments, ${ }^{16}$ where each para-substituted benzyl alcohol was allowed to compete with the parent benzyl alcohol in the alkylation of aniline. If no significant side reactions are occurring, disappearance of the starting material (either alcohol or aniline) can be used to monitor reaction progress. In this study we carried out GC analysis of the reaction mixtures, which allowed the consumption of each alcohol to be followed. If the reactions were of first order with respect to alcohol, the concentrations of the alcohols should follow the equation

$$
\operatorname{In}\left(\frac{X_{0}}{X}\right)=\frac{k_{X}}{k_{H}} \operatorname{In}\left(\frac{H_{0}}{H}\right)
$$

thus resulting in a series of linear plots; one for each para substituent. The subscript " 0 " stands for initial concentration, $X$ is the para-substituted alcohol and $H$ is benzyl alcohol itself. From these plots the relative reactivity of each para-substituted benzyl alcohol $\left(k_{\mathrm{X}} / k_{\mathrm{H}}\right)$ can easily be obtained as the slope of the line.

The reaction conditions for the Hammett study employing para-substituted benzyl alcohols are shown in Scheme 2. The initial assumptions regarding reaction orders are justified by the

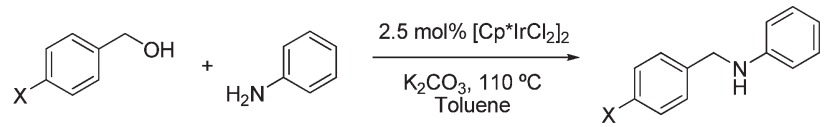

$\mathrm{X}=\mathrm{H}, \mathrm{NMe}_{2}, \mathrm{OMe}, \mathrm{Me}, \mathrm{Cl}, \mathrm{COOMe}, \mathrm{CF}_{3}, \mathrm{CN}, \mathrm{NO}_{2}$

Scheme 2 Alkylation of aniline with para-substituted benzyl alcohols as part of the Hammett study.

Table 1 Overview of Hammett study with para-substituted benzyl alcohols

\begin{tabular}{llllll}
\hline Entry & $\mathrm{X}$ & \multicolumn{1}{l}{$\sigma$} & $k_{\mathrm{X}} / k_{\mathrm{H}}$ & $\log \left(k_{\mathrm{X}} / k_{\mathrm{H}}\right)$ & $R^{2}$ \\
\hline 1 & $\mathrm{NMe}_{2}$ & -0.83 & 5.45 & 0.74 & 0.996 \\
2 & $\mathrm{OMe}$ & -0.27 & 1.94 & 0.29 & 0.999 \\
3 & $\mathrm{Me}$ & -0.17 & 1.61 & 0.21 & 0.999 \\
4 & $\mathrm{Cl}$ & 0.23 & 0.71 & -0.17 & 0.998 \\
5 & $\mathrm{COOMe}$ & 0.45 & 0.44 & -0.36 & 0.985 \\
6 & $\mathrm{CF}_{3}$ & 0.54 & 0.20 & -0.70 & 0.998 \\
7 & $\mathrm{CN}_{8}$ & 0.66 & 0.27 & -0.57 & 0.990 \\
8 & $\mathrm{NO}_{2}$ & 0.78 & 0.22 & -0.66 & 0.989 \\
\hline
\end{tabular}

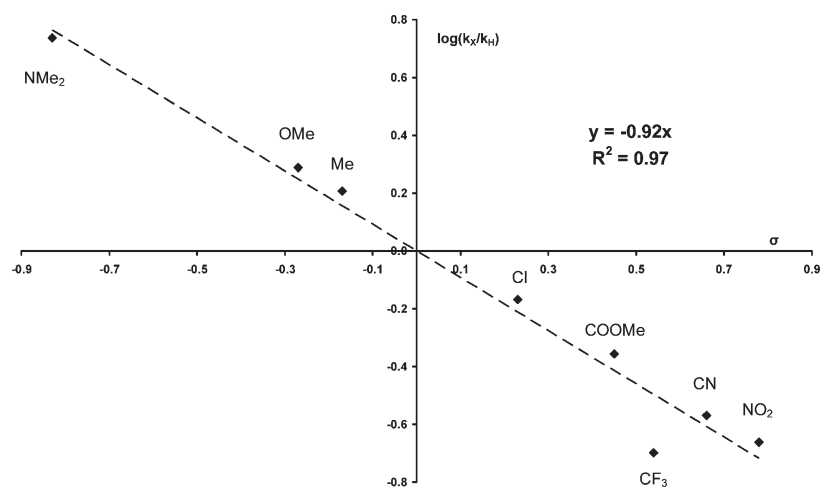

Fig. 1 Hammett plot obtained from competition experiments with a series of para-substituted benzyl alcohols.

plots, which all resulted in straight lines having $R^{2}>0.98$ (Table 1), and thus giving rise to accurate determinations of the relative reactivity $\left(k_{\mathrm{X}} / k_{\mathrm{H}}\right)$. For the ester substrate in entry 5 the lower correlation is probably due to partial degradation of the substrate through competing pathways such as transesterification and amidation. However, these side reactions are much slower than the amination and will therefore only play a role at very high conversions.

With the relative reactivities in hand and $\sigma$ values from the literature $^{15}$ the Hammett plot could be constructed (Fig. 1). The correlation is very good using the standard $\sigma$ values, indicating that neither cations nor radicals are involved in the selectivitydetermining step. Furthermore, the negative slope of the line indicates that a small positive charge is built up in the transition state.

In addition to the information gathered from the Hammett study, we were also interested in probing whether hydride abstraction takes place in the selectivity-determining step. This was investigated by measuring the primary kinetic isotope effect (KIE), using benzyl alcohol $\alpha, \alpha-\mathrm{d}_{2}$ in competition with paramethoxybenzyl alcohol under the standard reaction conditions. After correcting for the reactivity of the para-methoxybenzyl alcohol the kinetic isotope effect $\left(k_{\mathrm{H}} / k_{\mathrm{D}}\right)$ was found to be 2.48 . 


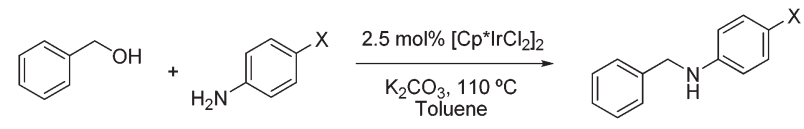

$\mathrm{X}=\mathrm{H}, \mathrm{NMe}_{2}, \mathrm{OMe}, \mathrm{Me}, \mathrm{Cl}, \mathrm{COOMe}, \mathrm{CF}_{3}, \mathrm{CN}$

Scheme 3 Alkylation of para-substituted anilines with benzyl alcohol as part of the second Hammett study.

Table 2 Overview of Hammett study with para-substituted anilines

\begin{tabular}{llrrcl}
\hline Entry & $\mathrm{X}^{a}$ & \multicolumn{1}{l}{$\sigma$} & $k_{\mathrm{X}} / k_{\mathrm{H}}$ & $\log \left(k_{\mathrm{X}} / k_{\mathrm{H}}\right)$ & $R^{2}$ \\
\hline $1^{b}$ & $\mathrm{NMe}_{2}$ & -0.83 & 29.12 & 1.46 & 0.995 \\
2 & $\mathrm{OMe}$ & -0.27 & 6.59 & 0.82 & 0.998 \\
3 & $\mathrm{Me}$ & -0.17 & 2.64 & 0.42 & 0.999 \\
4 & $\mathrm{Cl}$ & 0.23 & 0.44 & -0.35 & 0.993 \\
5 & $\mathrm{COOMe}$ & 0.45 & 0.22 & -0.66 & 0.984 \\
6 & $\mathrm{CF}_{3}$ & 0.54 & 0.07 & -1.18 & 0.960 \\
$7^{c}$ & $\mathrm{CN}$ & 0.66 & 0.05 & -1.33 & 0.979
\end{tabular}

${ }^{a} p$-Nitroaniline was completely insoluble and did not react under the standard reaction conditions. ${ }^{b}$ Competition experiment was performed with $p$-methoxyaniline as the competing substrate. ${ }^{c}$ Competition experiment was performed with $p$-chloroaniline as the competing substrate.

\section{Imine reduction}

According to the proposed mechanism (Scheme 1), the aldehyde reacts with the amine to form an imine, which is then reduced by the iridium-hydride complex to form an amine. In the simplest possible scenario this elementary step is just the reverse of the alcohol oxidation. However, we decided to carry out a separate Hammett study to elucidate this in further detail. Assuming that the formation of the imine is a fast reaction, the reduction of imines can be probed by competition experiments under similar conditions as in the previous study. Thus, different para-substituted anilines were allowed to compete with aniline in the reaction with benzyl alcohol as shown in Scheme 3. Again the competition experiments resulted in linear plots with a good correlation coefficient in most cases $\left(R^{2}>0.98\right)$, thus verifying that the reaction is also first order in aniline. In two cases a lower correlation coefficient was obtained (Table 2, entries 6 and 7) and this was due to large differences in rates between the two competing substrates. When the difference in rate is larger than $\sim 10$ the inaccuracies in the determination of the remaining substrate concentration hampers the correlation. ${ }^{17}$ However, since the Hammett equation employs the logarithm of the relative reactivities the impact of these uncertainties is small.

For the anilines there was a significantly larger reactivity span, which necessitated the use of substrates other than the parent aniline for the competition experiments with the most and the least reactive substrates. The data derived from the competition experiments involving different para-substituted anilines have been collected in Table 2 .

The kinetic data from Table 2 allows the construction of the Hammett plot using the standard $\sigma$ values (Fig. 2).

Again the best correlation is obtained with the standard $\sigma$ values, indicating that neither cations nor radicals are involved in this reaction. To our surprise the Hammett plot indicates that a positive charge is built up in the selectivity-determining transition state, which is not what would be expected from a simple

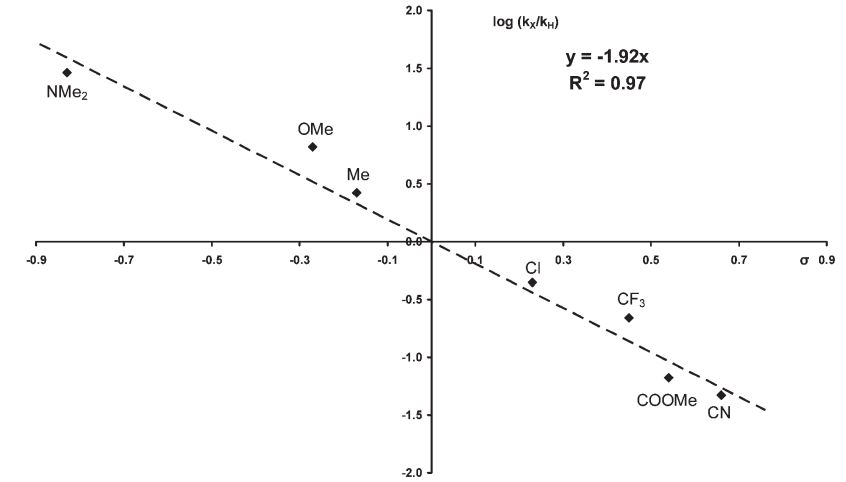

Fig. 2 Hammett plot obtained from competition experiments using a series of para-substituted anilines.

reduction of the intermediate imine by a metal-hydride complex. Instead, it may suggest that formation of the imine is indeed the selectivity-determining event. ${ }^{18}$ This could both be in the initial nucleophilic addition to form a hemiaminal or in the subsequent elimination of water since both steps should be accelerated by an electron-donating group. From the results obtained it was not possible to fully eliminate an alternative explanation, which involved a rapid exchange of the amine part in the imine. This has been reported to take place for imines, ${ }^{19}$ but under the current reaction conditions, the formed imine was readily reduced to the amine, thus minimising the possibility for exchange to occur. In a control experiment $N$-benzyl aniline and $p$-toluidine were subjected to the standard reaction conditions and GC did not reveal any exchange, strongly suggesting that such an exchange is slow compared to the forward reaction (i.e. reduction).

In both of the Hammett studies benzyl alcohol(s) were employed as substrates. However, if the catalytic cycle described so far is indeed operating under the actual experimental conditions, we envisioned that it should be possible to study the imine reduction step independently of the alcohol oxidation. In this way, we intended to use a sacrificial alcohol (e.g. 2-propanol) to form the iridium-hydride intermediate, which would then deliver the hydride to an imine already present in the reaction mixture. We were hoping to conduct competition experiments and perhaps even determining the kinetic isotope effect (using deuterated 2-propanol), but it was soon realised that such "transfer reduction" of imines does not occur under the standard experimental conditions. While this work was in progress, Yamaguchi and co-workers reported that a preformed imine is not transfer hydrogenated with 2-propanol, and suggested that the coupling of the amine and the aldehyde therefore must occur in the coordination sphere of iridium. ${ }^{3 g}$ Consequently, it may even be possible to run the reaction in the presence of a preformed imine without cross-reaction between the iridium-hydride and the preformed imine. We carried out this test experiment by reacting 2 mmol of benzyl alcohol and aniline under the standard conditions, and after 2 hours (conversions: benzyl alcohol: 0.24, aniline: 0.22 ) $N$-benzylidene $p$-methoxyaniline was added. Although the rate of the reaction decreased it did not stop and, more importantly, there was no detection of the reduced $\mathrm{N}$ benzyl-p-methoxyaniline which clearly shows that the imine is 
formed and consumed within the coordination sphere of the catalyst.

\section{Metal monohydride or dihydride}

Previously, Pàmies and Bäckvall have developed a method that makes it possible to investigate whether a metal-catalysed hydrogen transfer goes via a monohydride or a dihydride intermediate. ${ }^{13 g}$ The experiment involves the racemisation of a chiral alcohol, for which the amount of deuterium scrambling can be measured after the reaction. Absence of deuterium scrambling is indicative of a monohydride mechanism, in which the deuterium is always abstracted from and delivered to the same carbon atom, whereas complete scrambling indicates a dihydride intermediate where exchange of $\mathrm{H}$ and $\mathrm{D}$ can take place on the metal atom. For this purpose $(R)$-1-deutero-1-phenylethanol was synthesised $\left(81 \%\right.$ ee; $1 \% \mathrm{H}$ by NMR) and was subjected to the $\left[\mathrm{Cp}^{*} \mathrm{IrCl}_{2}\right]_{2}$ catalyst in the presence of an equimolar amount of acetophenone. Heating this mixture to $110{ }^{\circ} \mathrm{C}$ resulted in racemisation, as expected, and after five hours of reaction time ( $8 \%$ ee) 1-phenylethanol was reisolated. ${ }^{1} \mathrm{H}$ NMR spectroscopy revealed only little proton incorporation $(6 \%)$, which is a strong indication that a monohydride intermediate is involved. ${ }^{20}$

To further investigate the rate of the initial $\beta$-hydride abstraction a new KIE determination was performed and followed by GC and GC-MS. When competing $p$-chlorobenzyl alcohol with benzyl alcohol $\alpha, \alpha-\mathrm{d}_{2}$ we found that deuterium exchange does occur, however, the rate of this exchange is slower than the overall consumption of the benzyl alcohol. Thus, when analysing the initial part of the experiment we were able to obtain a KIE value close to the one determined earlier $\left(k_{\mathrm{H}} / k_{\mathrm{D}}=1.94\right)$. In the ESI $\uparrow$ we have included GC-MS data for both benzyl alcohol substrates and the obtained amine products, which confirms that the initially formed unsubstituted amine indeed contains a high amount of deuterium, as expected.

\section{Computational study}

As an extension of the experimental mechanistic study we have conducted a complementary computational investigation of the title reaction using density functional theory (DFT). In the current investigation we have used DFT in combination with the B3LYP hybrid functional, ${ }^{21}$ as implemented in the Jaguar from Schrodinger Inc., ${ }^{22}$ in line with earlier work on organometallic systems. ${ }^{23}$ This computational method has been used extensively during the last decade, and is characterised by a favourable ratio between accuracy and computational intensity. Recently, there have been concerns about the validity of DFT when dealing with, for example, enthalpies of formation, electrocyclic reactions and $\mathrm{C}-\mathrm{C}$ bond breaking reactions. ${ }^{24}$ However, when comparing isomeric structures many of the inherent short-comings of the B3LYP method will cancel out, and good agreement with experimental results can be obtained.

In conjunction with the B3LYP method, we have used the Hay-Wadt effective core potential (ECP) for iridium (denoted LACVP* in Jaguar), ${ }^{25}$ which have been parameterised to also include relativistic effects. Solvation is described using a selfconsistent reaction field (SCRF) polarised continuum model
(PCM) with parameters suitable for benzene (dielectric constant 2.284 and probe radius $2.6 \AA)^{26}$

For the most accurate determination of Gibbs free energies in solution we have chosen to use the single-point solvation energy for the fully optimised structure in vacuo. To this energy is then added the entropy contributions from analytical frequency calculations in vacuo. This was originally suggested by Wertz, ${ }^{27}$ and recently successfully applied by Lau and Deubel for palladium complexes. $^{28}$ In the current study we denote it $G_{\text {comb }}(298 \mathrm{~K})$ since it is a combination of solution phase energies and gas phase entropy. This approach has earlier been found to give results in accordance with experimental selectivities in cases where neither Gibbs Free energies in vacuo nor solvation energies were sufficiently accurate. ${ }^{16 b}$ Transition states displayed a single imaginary frequency, as expected, and was further characterised by IRC scan calculations.

In recent years it has become clear, however, that the B3LYP functional does not adequately describe the non-bonded interactions. This is a well-known deficiency of the B3LYP functional and the problem have been addressed by either appending a classic dispersion term ${ }^{29}$ or by using a functional which incorporates kinetic energy density terms. ${ }^{30}$ Among the most successful of the latter approaches are the M0x family of functionals reported by Zhao and Truhlar, and here we have chosen the M06 functional which have been optimised with particular focus on organometallic systems. ${ }^{31}$ Recently the M06 functional was necessary for the correct prediction of enantioselectivity in the palladium-catalysed allylic alkylation with a chiral ligand. ${ }^{32}$

\section{Dimer-monomer equilibrium for $\left[\mathrm{Cp}^{*} \mathrm{IrCl}_{2}\right]_{2}$}

Initially, the X-ray structure of $\left[\mathrm{Cp}^{*} \mathrm{IrCl}_{2}\right]_{2}$ was acquired from the CCDB database, ${ }^{33}$ hydrogen atoms were added and the structure optimised in the gas phase. The overall agreement between the X-ray structure and computed structure is good $(\mathrm{RMSD}=$ $0.0951 \AA$, excluding hydrogens), with the DFT structure having slightly longer $\mathrm{Ir}-\mathrm{Cl}$ and $\mathrm{Ir}-\mathrm{Cp}$ * bonds ( $c a .0 .005 \AA$ in both cases). The dimeric pre-catalyst $\left[\mathrm{Cp}^{*} \mathrm{IrCl}_{2}\right]_{2}$, which is an 18 electron complex, must dissociate to a monomeric 16-electron complex to allow coordination of the substrate alcohol. The simple dimer-monomer equilibrium (Scheme 4) was calculated using DFT/B3LYP, and the dimer is favoured by $10 \mathrm{~kJ} \mathrm{~mol}^{-1}$ in the gas phase (Gibbs free energy, $298 \mathrm{~K}$ ). In solution phase the dimer is also more stable by $30 \mathrm{~kJ} \mathrm{~mol}^{-1}$, but when the resulting $G_{\text {comb }}(298 \mathrm{~K})$ is calculated the monomer is favoured by $22 \mathrm{~kJ}$ $\mathrm{mol}^{-1}$. When applying the M06 functional that takes into account additional stabilising dispersion energy the dimer increases in stability by $65 \mathrm{~kJ} \mathrm{~mol}^{-1}$. When the reaction is carried out in refluxing toluene, formation of a small amount of the catalytically active monomer is thus favoured by entropy. ${ }^{34}$

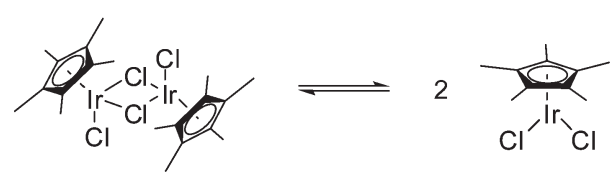

Scheme 4 Dimer-monomer equilibrium. 
Both the alcohol and the aniline substrates are competent ligands, which must be taken into consideration, in particular due to their high concentration under typical experimental conditions (catalyst loading $0.5-5 \mathrm{~mol} \%$ ). In contrast, the chloride counter-ion is only present in catalytic amounts and will be displaced by the better coordinating amines. Calculating the relative energies of $\mathrm{Cp}^{*} \mathrm{Ir}$ complexes with ammonia, water and chloride ligands showed that ammonia is a far better ligand than the other two. Under the experimental conditions employed here a colour change from colourless or slightly yellow to green is observed upon addition of the iridium catalyst. After a few minutes the solution turns brown, which may indicate a change of ligation state of the metal, suggesting that chloride is indeed being displaced. We assume the anionic, $\eta^{5}$-coordinated $\mathrm{Cp} *$ ligand remains coordinated to the metal during the entire catalytic cycle.

\section{Catalytic cycle}

In the organometallic chemistry of Ir(III) the "piano-stool" complexes are ubiquitous, which for the current reaction with a $\mathrm{Cp} *$ Ir moiety suggests that three additional ligands can be present. As already mentioned, one of them is probably an amine, which leaves two available coordination sites for the reacting alcohol. With a cationic metal centre the deprotonation of benzyl alcohol is favourable, although even for state-of-the-art computational methods the prediction of such an acid-base equilibrium is a formidable challenge and the inaccuracy is likely to be high. In any case, if the deprotonation has a lower barrier than the following $\beta$-hydride elimination it will not affect the overall rate of the reaction (Curtin-Hammett conditions). This rationale provides us with complex 1a as a plausible starting point for the catalytic reaction (Fig. 3).

From 1a $\beta$-hydride elimination takes place through transition state 1 b with a barrier of $39 \mathrm{~kJ} \mathrm{~mol}^{-1}\left(\Delta G_{\text {comb }}(298 \mathrm{~K})\right)$. The distances to the migrating hydride are typical for such transformations (C-H: $1.38 \AA$ and $\mathrm{Ir}-\mathrm{H}: 1.77 \AA$ ) as shown in Fig. 4. The calculated ESP charges $^{35}$ showed a significant increase of

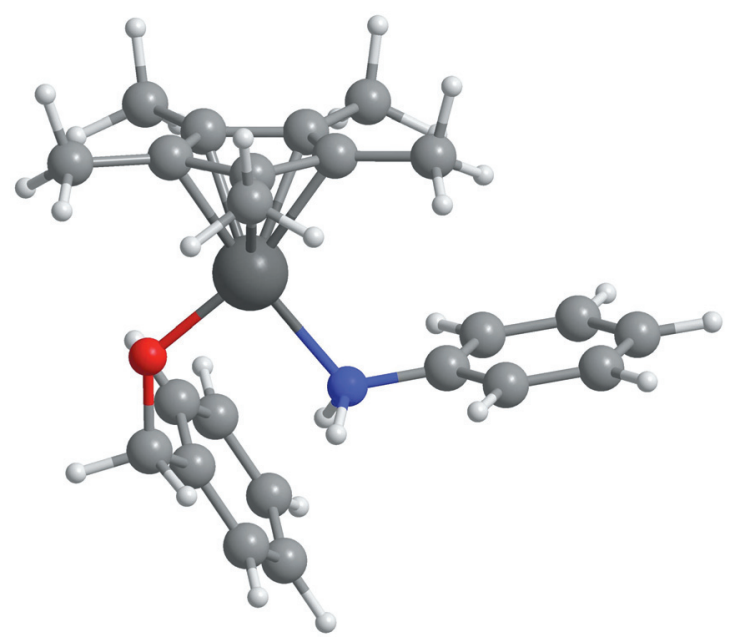

Fig. 3 Complex 1a with deprotonated benzyl alcohol coordinated to iridium. positive charge on the benzylic carbon in going from the precomplex $(\mathbf{1 a}:+0.10)$ to the TS $(\mathbf{1 b}:+0.31)$. This build up of positive charge is in excellent agreement with results from the experimental Hammett study using para-substituted benzyl alcohols.

When the $\beta$-hydride elimination has been completed, an iridium-aldehyde complex is formed (1c, Fig. 5) which is $6 \mathrm{~kJ}$ $\mathrm{mol}^{-1}$ lower in energy than the initial iridium-alkoxide complex 1a. While most earlier suggestions have indicated that dissociation of the aldehyde takes place at this point, we and others have shown experimentally that this exchange is slow compared to the forward reaction of the aldehyde (vide supra).

The aldehyde complex 1c can now undergo internal or external attack by an amine, which results in the formation of a hemiaminal after a proton shuttle from nitrogen to oxygen. If the attack is external the formation of the hemiaminal can be favoured by a bidentate coordination to the iridium centre and result in simultaneous or subsequent dissociation of the coordinated amine. Due to the many possibilities and the inherent low barriers for addition to the aldehyde we have focused on locating a reasonable structure for this hemiaminal intermediate (1d, Fig. 6).

With the computational methods applied here the relative energy for this intermediate is $42 \mathrm{~kJ} \mathrm{~mol}^{-1}$, and an additional proton shift to the oxygen results in spontaneous imine formation with extrusion of water (1e, $31 \mathrm{~kJ} \mathrm{~mol}^{-1}$, Fig. 7). The short $\mathrm{H}-\mathrm{H}$ distance $(1.89 \AA)$ between the hydride and the hydrogen on the phenyl group of the imine indicates a rather strong electrostatic interaction.

Interestingly, we found the cis-imine to be energetically slightly more favourable than the trans-imine, which is probably due to better coordination to the metal center. However, the interconversion between the two isomers were found to have a high barrier (see ESI $\uparrow$ for details), but perhaps a pathway involving dissociation of the loosely bound water ligand is more facile.

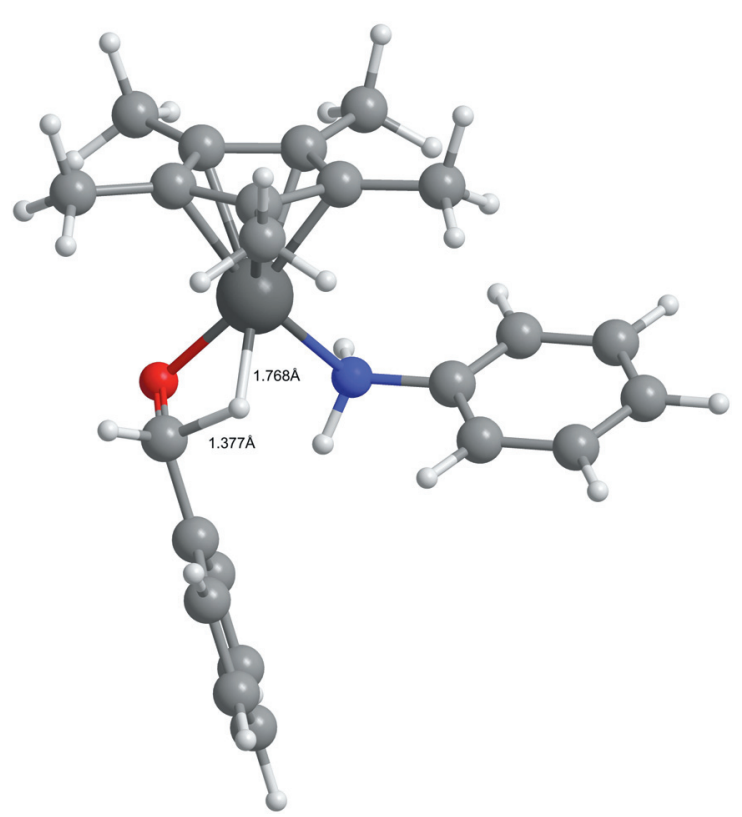

Fig. 4 Transition state $\mathbf{1 b}$ for $\beta$-hydride elimination. 


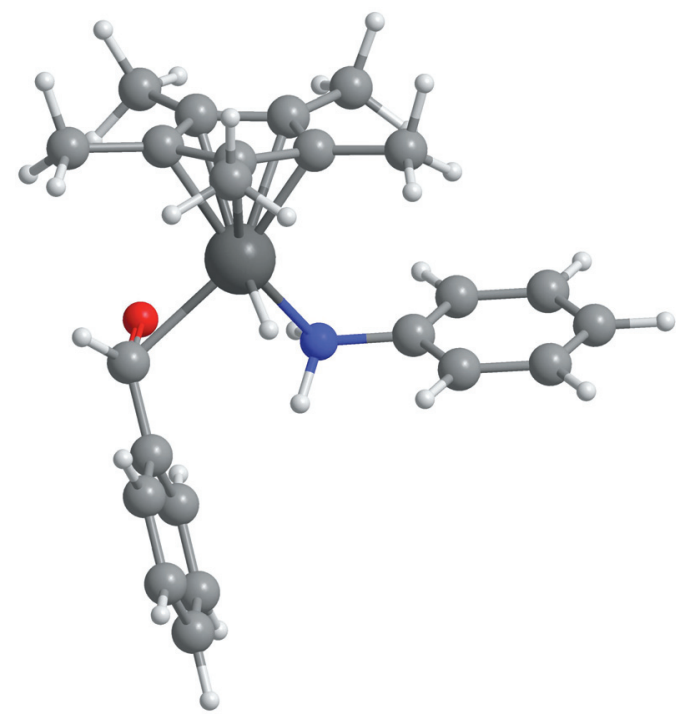

Fig. 5 Iridium-aldehyde complex 1 c formed after $\beta$-hydride elimination.

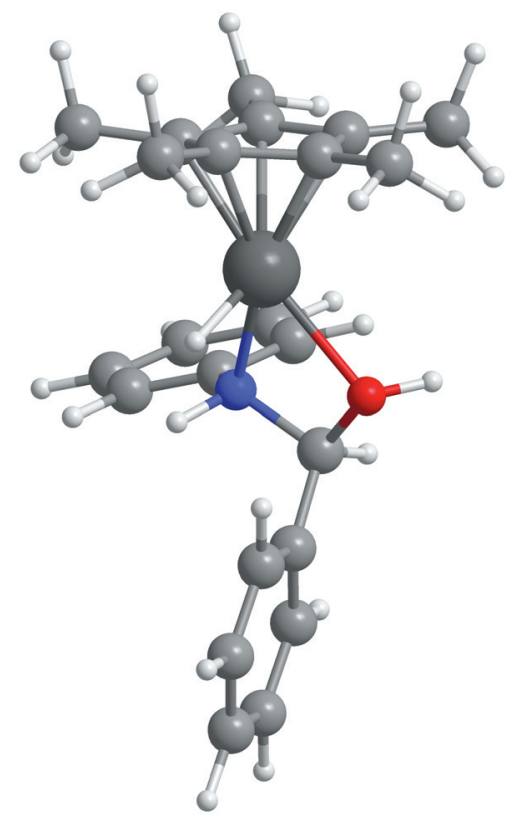

Fig. 6 Hemiaminal intermediate 1d coordinating to iridium in a bidentate fashion.

In order for the reduction of the imine by the Ir-H complex to take place, the complex must rearrange to a conformation where the hydride has the correct Bürgi-Dönitz angle for attack on the $\mathrm{sp}^{2}$-hybridised imine carbon. At the same time a ligand exchange from water to aniline could take place resulting in the structure 1f, Fig. 8).

From this complex the reduction can take place through a TS resembling the one found for oxidation of the alcohol $(\mathbf{1 g}$, Fig. 9).

The relative energy of the transition state $1 \mathrm{~g}$ is $94 \mathrm{~kJ} \mathrm{~mol}^{-1}$, which is the highest energy throughout the entire transformation (Fig. 10). After the reduction a relatively stable complex is

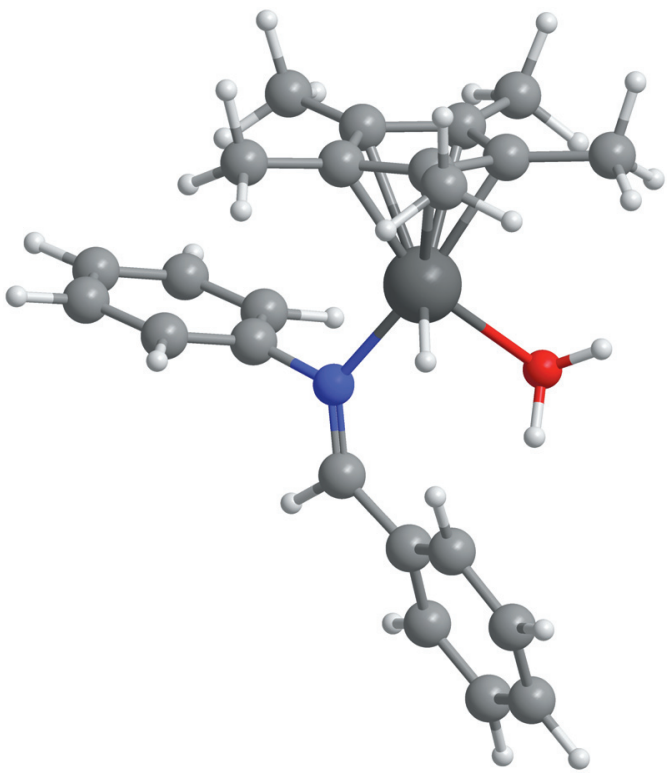

Fig. 7 Structure 1e with expelled water molecule coordinated to iridium.

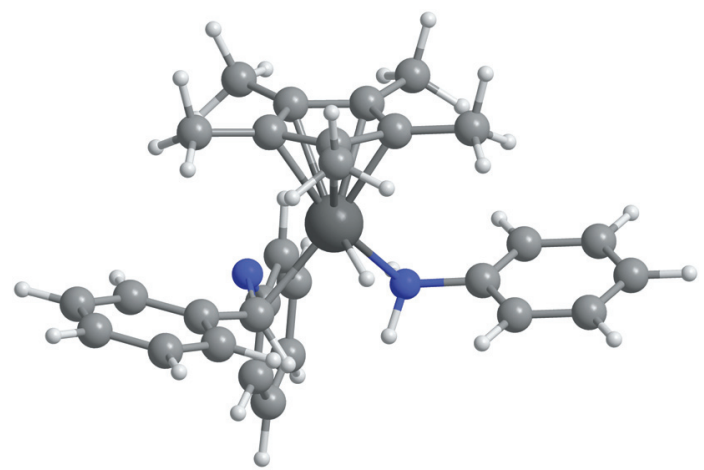

Fig. 8 Iridium-imine complex $\mathbf{1 f}$ with imine in position to receive the hydride.

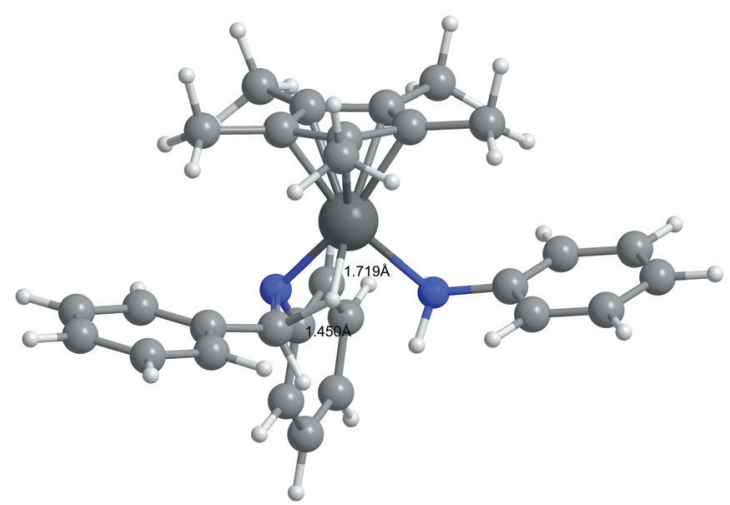

Fig. 9 Transition state $\mathbf{1 g}$ for reduction of imine by iridium-hydride.

formed with iridium coordinated to the deprotonated nitrogen of the amine (1h, Fig. 11), and a simple protonation will liberate the product and re-generate the catalyst. 


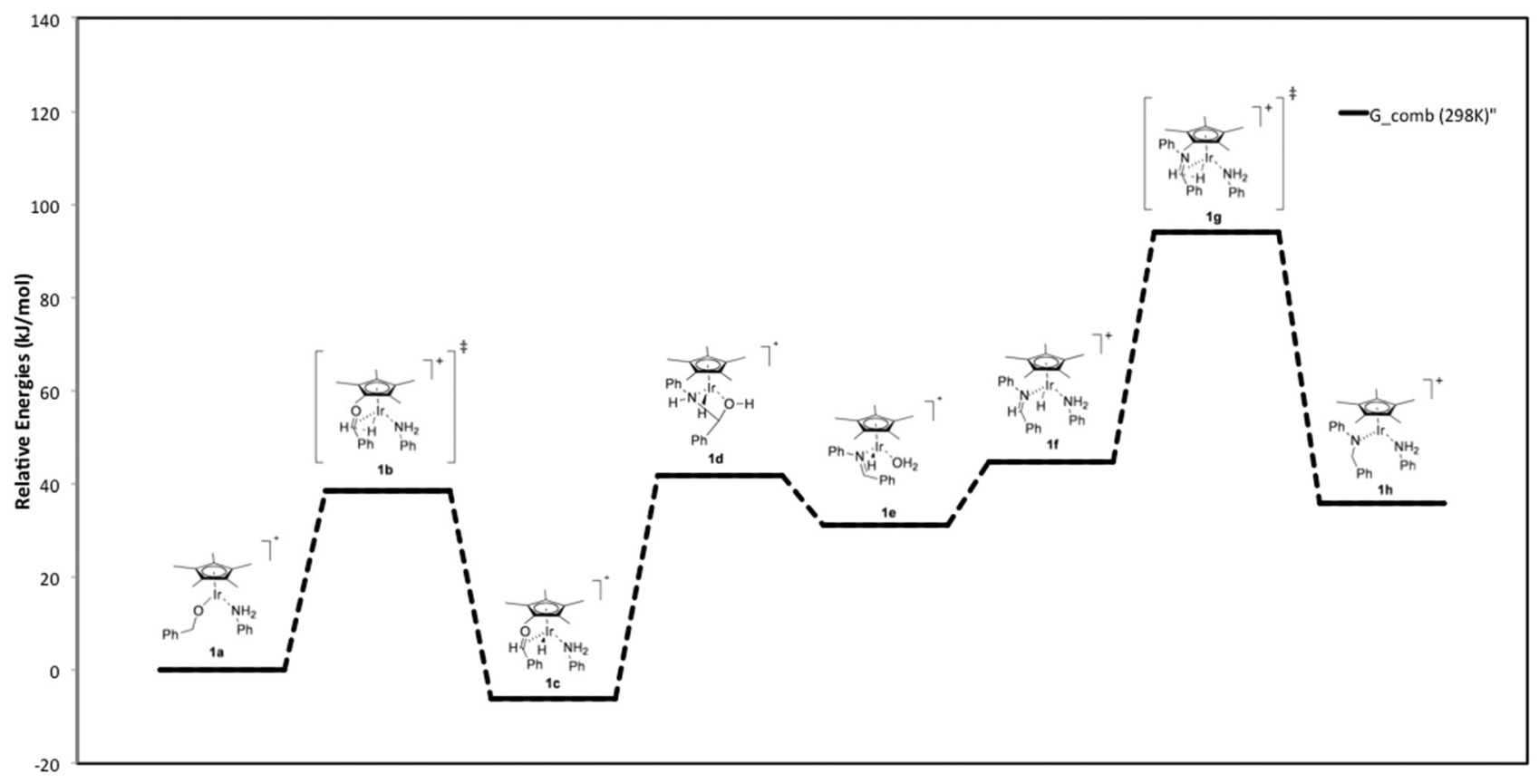

Fig. 10 Overview of the entire reaction pathway from benzyl alcohol complex 1a to benzyl amine complex $\mathbf{1 h}$.

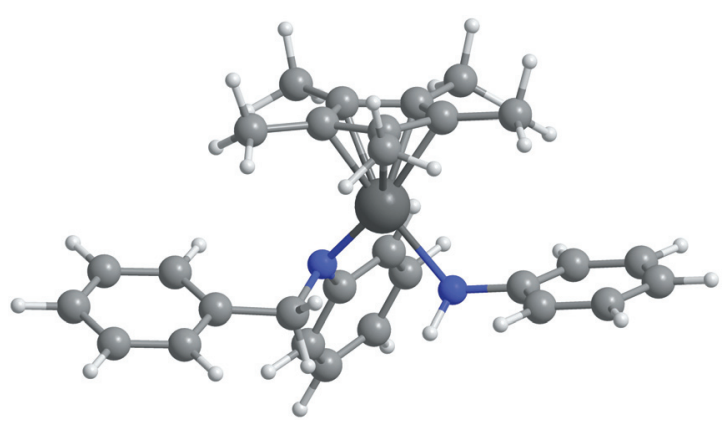

Fig. 11 Iridium-amine complex $\mathbf{1 h}$ formed after imine reduction.

With amines present in large excess under experimental conditions we do not favour the direct coordination of carbonate to iridium proposed by Crabtree, Eisenstein and co-workers. ${ }^{14}$ Furthermore, the reaction can be performed with a variety of different bases without large variations in reactivity as shown by Yamaguchi and co-workers. ${ }^{3 g}$

\section{Determination of theoretical KIE}

If we assume the $\mathrm{C}-\mathrm{H}(\mathrm{D})$ bond is fully broken in the transition state, one should expect a KIE of 4.5 at $110^{\circ} \mathrm{C}$ based solely on the differences in stretching frequencies $\left(\mathrm{C}-\mathrm{H}: 2900 \mathrm{~cm}^{-1}, \mathrm{C}-\mathrm{D}\right.$ : $\left.2100 \mathrm{~cm}^{-1}\right){ }^{36}$ The value obtained by the competition experiment was significantly lower (2.48), suggesting that the C-H-D bond indeed is broken in the selectivity-determining step, but that there is significant stabilisation of the formed hydride. With the calculated intermediates and transition states for the reaction sequence it is also possible to determine the KIE using transition state theory. For the initial $\beta$-hydride elimination a full

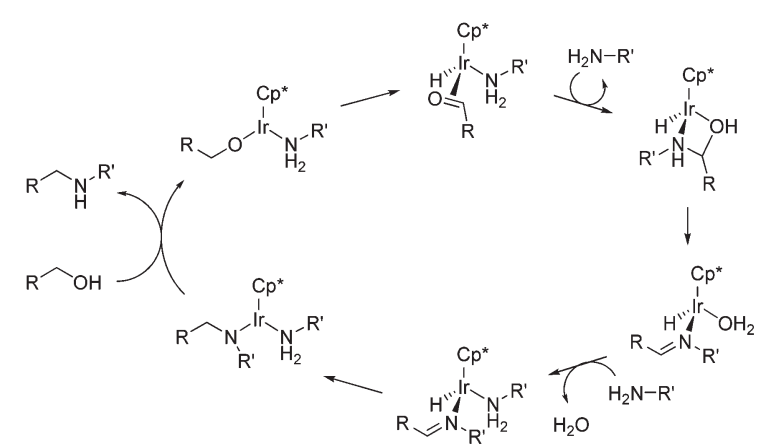

Scheme 5 Revised catalytic cycle for iridium-catalysed alkylation of amines with alcohols.

vibrational analysis with $T=110{ }^{\circ} \mathrm{C}$ results in a calculated KIE of 2.70 which is in good agreement with the experimental value.

\section{Conclusion}

Both experimental and theoretical studies suggest a catalytic cycle where the intermediate aldehyde does not leave the catalyst, but instead is attacked by the amine resulting in an iridiumhemiaminal intermediate (Scheme 5). This hemiaminal can then dehydrate to the imine, which is subsequently reduced to the amine, both steps taking place without breaking the coordination to the metal. The absence of conventional solution-phase imine formation may not have large implications for the model systems investigated here, but can be important when extending the reaction to more complicated substrates. The increased understanding of the mechanism will be valuable in order to further optimise and fine-tune this catalyst system. 


\section{Experimental}

Toluene was distilled from sodium-benzophenone ketyl under a nitrogen atmosphere. Reactions were carried out in oven-dried Schlenk tubes equipped with a cooling finger under an argon atmosphere. Aniline and $p$-(trifluoromethyl)aniline were distilled under reduced pressure; $p$-anisidine, $p$-toluidine were recrystallised from ethanol (with activated charcoal); $p$-(dimethylamino) benzyl alcohol was prepared according to a literature procedure. $^{37}\left[\mathrm{Cp}^{*} \mathrm{IrCl}_{2}\right]_{2}$ was obtained from ABCR, Germany. $N$ Benzylidene anilines and $N$-benzyl anilines were prepared by literature methods. $^{38,39}$ All other chemicals were obtained from commercial suppliers and used without further purification. GC analyses were performed on a Shimadzu GC-2010 instrument equipped with a Supelco Equity-1 capillary column $(30 \mathrm{~m} \times$ $0.25 \mathrm{~mm} \times 0.25 \mu \mathrm{m})$ and a FID detector. NMR spectra were recorded on a Varian Mercury 300 spectrometer in $\mathrm{CDCl}_{3}$ solution.

\section{General procedure for competition experiment with benzyl alcohols}

In an oven-dried Schlenk tube were placed $\mathrm{K}_{2} \mathrm{CO}_{3}(14 \mathrm{mg}$, $0.1 \mathrm{mmol})$, aniline $(180 \mu \mathrm{L}, 2 \mathrm{mmol})$, benzyl alcohol $(105 \mu \mathrm{L}$, $1 \mathrm{mmol}), p$-substituted benzyl alcohol (1 mmol), naphthalene (128 $\mathrm{mg}, 1 \mathrm{mmol})$ and dry toluene $(1 \mathrm{~mL})$. The mixture was placed in an oil bath preheated to $110{ }^{\circ} \mathrm{C}$ and a GC sample was taken out. Then, $\left[\mathrm{Cp}^{*} \mathrm{IrCl}_{2}\right]_{2}(40 \mathrm{mg}, 0.05 \mathrm{mmol})$ was added. This resulted in an immediate colour change from original colourless/yellow to dark green, which in a few minutes changed to brown, and then remained brown for the rest of the experiment. The mixture was stirred at $110{ }^{\circ} \mathrm{C}$ and samples were taken out for $\mathrm{GC}$ analysis as shown in the $\mathrm{ESI} \uparrow$ for each experiment.

\section{General procedure for competition experiment with anilines}

In an oven-dried Schlenk tube were placed $\mathrm{K}_{2} \mathrm{CO}_{3}(14 \mathrm{mg}$, $0.1 \mathrm{mmol})$, aniline (90 $\mu \mathrm{L}, 1 \mathrm{mmol}), p$-substituted aniline (1 mmol), benzyl alcohol (210 $\mu \mathrm{L}, 2 \mathrm{mmol})$, naphthalene (128 $\mathrm{mg}, 1 \mathrm{mmol})$ and dry toluene $(1 \mathrm{~mL})$. The mixture was placed in an oil bath preheated to $110{ }^{\circ} \mathrm{C}$ and a sample for GC was taken out. Then, $\left[\mathrm{Cp}^{*} \mathrm{IrCl}_{2}\right]_{2}(40 \mathrm{mg}, 0.05 \mathrm{mmol})$ was added. This resulted in an immediate colour change from original colourless/yellow to dark green, which in few minutes changed to brown and then remained brown for the rest of the experiment. The mixture was stirred at $110{ }^{\circ} \mathrm{C}$ and samples were taken out for GC analysis as shown in the ESI $\uparrow$ for each experiment.

\section{Acknowledgements}

We thank the Danish National Research Foundation and the Danish Council for Independent Research, Technology and Production Sciences for financial support.

\section{References}

1 (a) C.-J. Li and B. M. Trost, Proc. Natl. Acad. Sci. U. S. A., 2008, 105, 13197-13202; (b) R. A. Sheldon, Chem. Commun., 2008, 3352-3365; (c) K. Alfonsi, J. Colberg, P. J. Dunn, T. Fevig, S. Jennings, T. A. Johnson, H. P. Kleine, C. Knight, M. A. Nagy, D. A. Perry and M. Stefaniak, Green Chem., 2008, 10, 31-36.

2 (a) A. J. A. Watson, A. C. Maxwell and J. M. J. Williams, J. Org. Chem., 2011, 76, 2328-2331; (b) S. Bähn, S. Imm, K. Mevius, L. Neubert, A. Tillack, J. M. J. Williams and M. Beller, Chem.-Eur. J., 2010, 16, 3590-3593; (c) M. H. S. A. Hamid, C. L. Allen, G. W. Lamb, A. C. Maxwell, H. C. Maytum, A. J. A. Watson and J. M. J. Williams, J. Am. Chem. Soc., 2009, 131, 1766-1774; (d) D. Hollmann, A. Tillack, D. Michalik, R. Jackstell and M. Beller, Chem.-Asian J., 2007, 2, 403410; (e) Y. Tsuji, K.-T. Huh and Y. Watanabe, J. Org. Chem., 1987, 52, $1673-1680$.

3 (a) I. Cumpstey, S. Agrawal, K. E. Borbas and B. Martín-Matute, Chem. Commun., 2011, 47, 7827-7829; (b) R. Kawahara, K.-i. Fujita and R. Yamaguchi, Adv. Synth. Catal., 2011, 353, 1161-1168; (c) O. Saidi, A. J. Blacker, M. M. Farah, S. P. Marsden and J. M. J. Williams, Chem. Commun., 2010, 46, 1541-1543; (d) N. Andrushko, V. Andrushko, P. Roose, K. Moonen and A. Börner, ChemCatChem, 2010, 2, 640-643; (e) B. Blank, S. Michlik and R. Kempe, Chem.-Eur. J., 2009, 15, 3790 3799; $(f)$ A. Prades, R. Corberán, M. Poyatos and E. Peris, Chem.-Eur. J., 2008, 14, 11474-11479; (g) K.-i. Fujita, Y. Enoki and R. Yamaguchi, Tetrahedron, 2008, 64, 1943-1954; (h) G. Cami-Kobeci, P. A. Slatford, M. K. Whittlesey and J. M. J. Williams, Bioorg. Med. Chem. Lett., 2005, 15, 535-537.

4 R. Yamaguchi, K.-i. Fujita and M. Zhu, Heterocycles, 2010, 81, $1093-$ 1140 .

5 K.-i. Fujita, T. Fujii, A. Komatsubara, Y. Enoki and R. Yamaguchi, Heterocycles, 2008, 74, 673-682.

6 (a) K.-i. Fujita, Y. Kida and R. Yamaguchi, Heterocycles, 2009, 77, 1371-1377; (b) L. U. Nordstrøm and R. Madsen, Chem. Commun., 2007, 5054-5056.

7 (a) R. N. Monrad and R. Madsen, Org. Biomol. Chem., 2011, 9, 610 615; (b) H. Aramoto, Y. Obora and Y. Ishii, J. Org. Chem., 2009, 74, 628-633.

8 (a) M. Tursky, L. L. R. Lorentz-Petersen, L. B. Olsen and R. Madsen, Org. Biomol. Chem., 2010, 8, 5576-5582; (b) S. Whitney, R. Grigg, A. Derrick and A. Keep, Org. Lett., 2007, 9, 3299-3302; (c) K.-i. Fujita, K. Yamamoto and R. Yamaguchi, Org. Lett., 2002, 4, 2691-2694.

9 K.-i. Fujita and R. Yamaguchi, Synlett, 2005, 560-571.

10 (a) B. L. Conley, M. K. Pennington-Boggio, E. Boz and T. J. Williams, Chem. Rev., 2010, 110, 2294-2312; (b) A. Comas-Vives, G. Ujaque and A. Lledós, THEOCHEM, 2009, 903, 123-132; (c) J. S. M. Samec, J.E. Bäckvall, P. G. Andersson and P. Brandt, Chem. Soc. Rev., 2006, 35, 237-248.

11 For recent examples, see: (a) M. C. Warner, O. Verho and J.-E. Bäckvall, J. Am. Chem. Soc., 2011, 133, 2820-2823; (b) C. A. Sandoval, F. Bie, A. Matsuoka, Y. Yamaguchi, H. Naka, Y. Li, K. Kato, N. Utsumi, K. Tsutsumi, T. Ohkuma, K. Murata and R. Noyori, Chem.-Asian J., 2010, 5, 806-816; (c) J. Wettergren, E. Buitrago, P. Ryberg and H. Adolfsson, Chem.-Eur. J., 2009, 15, 5709-5718; (d) N. Pannetier, J.P. Sortais, P. S. Dieng, L. Barloy, C. Sirlin and M. Pfeffer, Organometallics, 2008, 27, 5852-5859; (e) X. Wu, J. Liu, D. D. Tommaso, J. A. Iggo, C. R. A. Catlow, J. Bacsa and J. Xiao, Chem.-Eur. J., 2008, 14, 76997715; $(f)$ W. Baratta, K. Siega and P. Rigo, Chem.-Eur. J., 2007, 13, 7479-7486; ( $g$ ) B. Martín-Matute, J. B. Åberg, M. Edin and J.E. Bäckvall, Chem.-Eur. J., 2007, 13, 6063-6072; (h) J. S. M. Samec, A. H. Éll, J. B. Åberg, T. Privalov, L. Eriksson and J.-E. Bäckvall, J. Am. Chem. Soc., 2006, 128, 14293-14305; (i) C. P. Casey, G. A. Bikzhanova and I. A. Guzei, J. Am. Chem. Soc., 2006, 128, 2286-2293.

12 For recent examples, see: (a) J. Bosson, A. Poater, L. Cavallo and S. P. Nolan, J. Am. Chem. Soc., 2010, 132, 13146-13149; (b) A. Nova, D. Balcells, N. D. Schley, G. E. Dobereiner, R. H. Crabtree and O. Eisenstein, Organometallics, 2010, 29, 6548-6558; (c) N. Sieffert and M. Bühl, J. Am. Chem. Soc., 2010, 132, 8056-8070; (d) A. ComasVives, G. Ujaque and A. Lledós, Organometallics, 2007, 26, 4135-4144; (e) J.-W. Handgraaf and E. J. Meijer, J. Am. Chem. Soc., 2007, 129, 3099-3103; $(f)$ T. Privalov, J. S. M. Samec and J.-E. Bäckvall, Organometallics, 2007, 26, 2840-2848.

13 (a) K.-i. Fujita, T. Yoshida, Y. Imori and R. Yamaguchi, Org. Lett., 2011, 13, 2278-2281; (b) H. Li, G. Lu, J. Jiang, F. Huang and Z.-X. Wang, Organometallics, 2011, 30, 2349-2363; (c) C. Azerraf and D. Gelman, Chem.-Eur. J., 2008, 14, 10364-10368; (d) F. Hanasaka, K.-i. Fujita and R. Yamaguchi, Organometallics, 2005, 24, 3422-3433; (e) J.W. Handgraaf, J. N. H. Reek and E. J. Meijer, Organometallics, 2003, 22, 3150-3157; (f) M. Albrecht, J. R. Miecznikowski, A. Samuel, J. 
W. Faller and R. H. Crabtree, Organometallics, 2002, 21, 3596-3604; (g) O. Pàmies and J.-E. Bäckvall, Chem.-Eur. J., 2001, 7, 5052-5058; (h) K. Mashima, T. Abe and K. Tani, Chem. Lett., 1998, 1201-1202. See also ref. $3 b$.

14 D. Balcells, A. Nova, E. Clot, D. Gnanamgari, R. H. Crabtree and O. Eisenstein, Organometallics, 2008, 27, 2529-2535.

15 C. Hansch, A. Leo and R. W. Taft, Chem. Rev., 1991, 91, 165-195.

16 (a) J. H. Dam, P. Fristrup and R. Madsen, J. Org. Chem., 2008, 73, 3228-3235; (b) P. Fristrup, M. Kreis, A. Palmelund, P.-O. Norrby and R. Madsen, J. Am. Chem. Soc., 2008, 130, 5206-5215; (c) L. Keinicke, P. Fristrup, P.-O. Norrby and R. Madsen, J. Am. Chem. Soc., 2005, 127, $15756-15761$.

17 P. Fristrup, G. H. Jensen, M. L. N. Andersen, D. Tanner and P.O. Norrby, J. Organomet. Chem., 2006, 691, 2182-2198.

18 E. F. Pratt and M. J. Kamlet, J. Org. Chem., 1961, 10, 4029-4031.

19 (a) G. Reddelien, Ber., 1920, 53B, 355-358; (b) N. Giuseppone, J.L. Schmitt, E. Schwartz and J.-M. Lehn, J. Am. Chem. Soc., 2005, 127, $5528-5539$

20 Very recently, Yamaguchi and co-workers reported the alkylation of amines with alcohols in water in the presence of the related complex $\left[\mathrm{Cp} * \operatorname{Ir}\left(\mathrm{NH}_{3}\right)_{3}\right] \mathrm{I}_{2}$ (ref. $3 b$ ). Deuterium scrambling experiments did also in this case indicate a reaction pathway with an iridium monohydride intermediate.

21 (a) A. D. Becke, J. Chem. Phys., 1993, 98, 5648-5652; (b) A. D. Becke, J. Chem. Phys., 1993, 98, 1372-1377; (c) C. Lee, W. Yang and R. G. Parr, Phys. Rev. B, 1988, 37, 785-789.

22 Jaguar, version 7.0, Schrödinger, LLC, New York, NY, 2007, release 107. For the most recent version, see: http://www.schrodinger. com..

23 (a) P. Fristrup, M. Ahlquist, D. Tanner and P.-O. Norrby, J. Phys. Chem. A, 2008, 112, 12862-12867; (b) N. Svensen, P. Fristrup, D. Tanner and P.-O. Norrby, Adv. Synth. Catal., 2007, 349, 2631-2640; (c) M. Ahlquist, P. Fristrup, D. Tanner and P.-O. Norrby, Organometallics, 2006, 25, 2066-2073.

24 For an overview, see: P. R. Schreiner, Angew. Chem., Int. Ed., 2007, 46, $4217-4219$
25 LACVP* uses the 6-31G* basis set for all light elements and the HayWadt ECP and basis set for Ir, see: P. J. Hay and W. R. J. Wadt, J. Chem. Phys., 1985, 82, 299-310.

26 (a) B. Marten, K. Kim, C. Cortis, R. A. Friesner, R. B. Murphy, M. N. Ringnalda, D. Sitkoff and B. Honig, J. Phys. Chem., 1996, 100, 11775-11788; (b) D. J. Tannor, B. Marten, R. Murphy, R. A. Friesner, D. Sitkoff, A. Nicholls, M. Ringnalda, W. A. Goddard, III and B. Honig, J. Am. Chem. Soc., 1994, 116, 11875-11882.

27 D. H. Wertz, J. Am. Chem. Soc., 1980, 102, 5316-5322.

28 J. K.-C. Lau and D. V. Deubel, J. Chem. Theory Comput., 2006, 2, $103-$ 106.

29 (a) M. Elstner, P. Hobza, T. Frauenheim, S. Suhai and E. Kaxiras, $J$. Chem. Phys., 2001, 114, 5149-5155; (b) S. Grimme, J. Comput. Chem., 2004, 25, 1463-1473.

30 Y. Zhao, N. E. Schultz and D. G. Truhlar, J. Chem. Theory Comput., 2006, 2, 364-382.

31 (a) Y. Zhao and D. G. Truhlar, Theor. Chem. Acc., 2008, 120, 215-241; (b) Y. Zhao and D. G. Truhlar, Acc. Chem. Res., 2008, 41, 157-167.

32 X. Bantreil, G. Prestat, A. Moreno, D. Madec, P. Fristrup, P.-O. Norrby, P. S. Pregosin and G. Poli, Chem. Eur. J., 2011, 17, 2885-2896.

33 M. R. Churchill and S. A. Julis, Inorg. Chem., 1977, 16, 14881494Refcode: DCPMIR; See ESI $\uparrow$ for further details.

34 D. S. Gill, C. White and P. M. Maitlis, J. Chem. Soc., Dalton Trans., 1978, 617-626.

35 L. E. Chirlian and M. M. Francl, J. Comput. Chem., 1987, 8, 894-905.

36 F. H. Westheimer, Chem. Rev., 1961, 61, 265-273.

37 M. R. Pitts, J. R. Harrison and C. J. Moody, J. Chem. Soc., Perkin Trans. 1, 2001, 955-977.

38 (a) H. Neuvonen, K. Neuvonen and F. Fülöp, J. Org. Chem., 2006, 71, 3141-3148; (b) J. H. Billman and A. C. Diesing, J. Org. Chem., 1957, 22, 1068-1070.

39 For characterisation data of N-benzyl anilines, see: C.-Y. Tsai, R. Sung, B.-R. Zhuang and K. Sung, Tetrahedron, 2010, 66, 6869-6872; S. C. A. Sousa and A. C. Fernandes, Adv. Synth. Catal., 2010, 352, 2218-2226; C.-T. Yang, Y. Fu, Y.-B. Huang, J. Yi, Q.-X. Guo and L. Liu, Angew. Chem., Int. Ed., 2009, 48, 7398-7401; ref. $3 b$ and $3 g$. 